\title{
Alcohol Consumption
}

National Cancer Institute

\section{Source}

National Cancer Institute. Alcohol Consumption. NCI Thesaurus. Code C16273.

Consumption of liquids containing ethanol, including the behaviors associated with drinking the alcohol. 